\title{
Evaluation of Intersection Properties Using MARS Method for Improving Urban Traffic Performance: Case Study of Tekirdağ, Turkey
}

\author{
Görkem GÜLHAN ${ }^{1}$ \\ Mustafa ÖZUYSAL ${ }^{2}$ \\ Hüseyin CEYLAN ${ }^{3}$
}

\begin{abstract}
Increasing urban traffic performance is a technical problem that has been investigated by many researchers these days. Traffic performance can be increased in many ways, as part of the transportation planning process, on smaller scales, or with different methods and techniques. The determination of traffic intervention areas in urban transportation planning is an intervention type that determines the rate at which the traffic performance will increase. Although transportation planning is an integrated issue, the type of traffic modification and prior intervention on intersections are often determined with partitive paradigms and strategies. It is a significant opportunity for decision makers to be informed in advance of the effects of intersection characteristics on the overall traffic performance. However, it is not an attempted or tested concept to perform a general assessment of the impact of the intersection characteristics on the overall performance of the intersections. In this study, a four-stage integrated analysis including the multivariate adaptive regression splines (MARS) method is proposed for the overall traffic performance evaluation. The traffic characteristics of intersections are first indexed and categorized. The intersection performance results are then obtained using the VISSIM traffic simulation software. Subsequently, the relationship between them is determined with the MARS method, and the effects of the intersection characteristics on the traffic performance are investigated. Tekirdağ, a metropolitan city located in northwestern Turkey, is selected for the case study. According to the obtained simulation results, the suggestions related to the development of intersection performances are made and tested.
\end{abstract}

Note:

- This paper was received on April 8, 2019 and accepted for publication by the Editorial Board on May 23, 2020.

- Discussions on this paper will be accepted by January 31, 2022.

- https://dx.doi.org/10.18400/tekderg.551032

1 Pamukkale University, Dept. of Urban and Regional Planning, Denizli, Turkey - ggulhan@pau.edu.tr https://orcid.org/0000-0003-2715-0984

2 Dokuz Eylül University, Department of Civil Engineering, İzmir, Turkey - mustafa.ozuysal@deu.edu.tr https://orcid.org/0000-0002-3276-3075

3 Pamukkale University, Department of Civil Engineering, Denizli, Turkey - hceylan@pau.edu.tr https://orcid.org/0000-0002-8840-4936 
Keywords: Traffic performance, VISSIM, intersection, Multivariate Adaptive Regression Splines.

\section{INTRODUCTION}

In the last decades, the spread of land use and motorized travel demand in urban areas have increased based on the growing urbanization. On the other hand, people are spending more time in traffic owing to the increasing travel distances and durations even on normal (steady state) traffic conditions. Considering the typical incidents (i.e., accidents, car breakdowns, lane blockages from construction activities, bad weather conditions), traffic flow is interrupted and unpredictable delays occur [1]. In this context, many researchers have handled delay and travel time minimization problems on the network and arterial levels. Most typical studies on the network level focus on the transportation network design problem, in which some traffic control strategies are introduced to calculate the intersection signal timings more accurately, or topologies of the network elements (i.e., parking places, road closure schemes, lane addition, lane allocation) are redesigned [2-8]. On the other hand, the performance analyses of urban arterials are primarily evaluated in terms of the average travel time, which is a function of signal timing parameters of adjacent intersections and traffic flow patterns under different levels of congestion [9-10]. Therefore, several studies focus on signal timing and offset optimization on urban arterials [11-15]. When viewed from this aspect, intersections appear to be the key point to provide shorter travel times and decrease the level of congestion on the roads. Because the intersections are the most critical components of the road transportation systems, they must be designed and operated based on the advanced methodologies to determine the most appropriate solution. Thus, the project level requirements can be satisfied by addressing the site constraints [16]. In the relevant literature, congestion management strategies have widely been investigated based on the geometric designs or operational improvements of signalized intersections (i.e., cycle time determination, green split calculations, phase planning).

Intersection geometry and physical element improvements may be interpreted as the most recognized intersection intervention types. The total delay time, queue length, capacity, and safety performance of an intersection is directly related to the geometric design itself. Otković and Dadić [17] compared the delays at a roundabout and a conventional signal-controlled intersection in Osijek city. They found that the delay times could be decreased significantly at roundabouts in comparison with the signalized intersections. Furthermore, a number of studies outlined that the roundabouts provided safer driving environments by decreasing all crashes from $21 \%$ to $61 \%$ [18-20]. While the increasing trend on replacing conventional signalized intersections with roundabouts has continued, designing unconventional intersections has also been emphasized by researchers [21-30]. As reported in the previous research, geometrically different designed intersections provide different levels of operational and safety performance. Apart from the geometric adjustments on isolated intersections via converting them into roundabouts or unconventional types, signal timing improvements has widely been studied in the past. Lan [31] proposed a new cycle time calculation approach based on nonlinear regression analysis to reveal the relationship between cycle time and traffic flow pattern based on the total lost time, critical flow ratio, and duration of analysis period. Results of the study showed that the generated optimal cycle length is only $5.7 \%$ deviated from the analytical solution. Talmor and Mahalel [32] proposed 
a signal timing design method for an isolated intersection under severe congestion conditions. They showed that designing the signal timing parameters by considering the throughput function, instead of the saturation flow function, might increase the discharge capacity of a signalized intersection. Yu et al. [33] presented a multi-objective optimization problem including capacity, delay time, number of stops, and emissions with their related weights determined by the fuzzy compromise programming approach. In their study, the objective function value is minimized using genetic algorithm, and the results showed that the capacity of the intersection could be improved by reducing the vehicle delays and number of stops. As shown above, several studies concerning intersection performance improvements have focused on either the intersection geometry or signal timing calculations based on prior decisions. In other words, the planner has already decided to convert a signalized intersection into a roundabout or an unconventional intersection; subsequently, the research is built on this prior decision. Likewise, the planner may have decided to increase the performance of a signalized intersection by only changing the stage plan, cycle time, and green times. In either case, it is assumed that the planner can provide the right decision. However, considering a significant variety of factors affecting the performance of an intersection, developing an integrated approach would be useful for policy makers and planners because prejudiced decisions may lead to time loss or missing a better solution alternative. This approach may be developed using regression models by identifying the intersection performance as the dependent variable within different perspectives (i.e., average speed, travel time, delay time, and number of stops). Meanwhile, several factors affecting the intersection performance may be treated as the independent variables. Therefore, the most important determinants of the intersection performance would be identified and policy makers can be supported for the efficient use of resources.

This study employs a novel estimation technique, the multivariate adaptive regression spline (MARS) model that has been widely applied in many scientific fields. MARS is a method providing flexibility to consider nonlinear effects of explanatory variables using the partial adaptation of spline functions [34]. Additionally, MARS can provide threshold values of explanatory variables where the effects on dependent variables considerably change [35]. As the intersection performance depends on miscellaneous factors such as traffic characteristics (volume, composition, moving directions, etc.), control type (signalization, give way, etc.), geometry (lane number and width, dimensions, medians, etc.) and immediate surroundings (close intersections, bus stops, etc.), linear approaches cannot adequately predict the intersection performance. Additionally, parametric predictions including threshold values of independent variables that should not be exceeded in intersection design (maximum cycle time, maximum roundabout diameter, etc.) are essential to obtain the basic principles for practitioners. Thus, more accurate and substantive results may be obtained in performance prediction using the MARS approach. As mentioned before, studies on intersection performance improvements are based on the assumption that intersection control type and geometric structure are predetermined. However, improving a particular intersection depending on the parameters initially adopted may prevent the planner from making a much more efficient planning. By using the proposed approach in this study, it may be possible to simultaneously evaluate a great variety of data reflecting geometric characteristics, control type and traffic flow patterns in terms of the performance of a given intersection. Once the model results are justified on a valid sample size, intersection performance estimation can be obtained without using expensive and time-consuming micro simulation models. Therefore, 
it is expected to bring a new perspective, which may be identified as a holistic point of view, to the investigation of intersection performance analysis.

In this context, a four-step integrated approach is developed to determine several independent variables' (i.e., intersection control type, intersection geometry type, number of legs, number of enter/exit lanes, signal timings, traffic flow characteristics, number and distance of bus stops around, intersection size) impact on eight intersection performance indicators by employing the MARS model. The values of the performance indicators are obtained using microsimulations by the VISSIM software. Based on the modelling results, the most efficient relationships between the intersection properties and performance indicators are determined, and explanatory information on how to achieve targeted improvements in the intersection performance is provided for policy makers and planners. At the final step of the proposed approach, a demonstration is provided to show that the MARS model predictions may effectively be used to examine and improve the performance of an existing intersection.

The remainder of the paper is organized as follows: The next section presents the method and study area. The analyses are provided in section 3 including the indexing of intersections, the MARS model results, and the selection and testing of intersection design parameters. Finally, section 4 presents the conclusions and some suggestions for future directions.

\section{METHOD \& STUDY AREA}

\subsection{Method}

The aim of this study is to offer an effective traffic improvement planning by considering the intersection characteristics and performance on decision levels. Hence, a stepwise paradigm has been offered and each level has been defined, as shown in Fig. 1.

Step 1; starts with the description and indexing of intersection features. Intersections have many characteristics, and the determination of those characteristics to use them for generating intersection modification strategies is substantial. Those characteristics may be the leg green times according to their directions, saturated leg flows, traffic volumes and ratios according to their types and directions, saturation rate, square diameters, square lane numbers, average approach square existence, existence of roundabouts, average number of lane widths, existence of bus stop and their distances to the intersections, number of lanes, existence of intermediate refuge, turn pads, existence of intersections nearby, dimensions of intersection, number of legs, phase numbers, signal cycle times, and signaling status. These can be grouped into four primary parts: traffic-, geometric-, and control-related features and immediate surroundings. The derived intersection characteristics for the study are shown in Tables 1a and 1b. While the characteristics, especially the control-related ones are specific, most of the traffic-related and geometric parameters are generic except the roundabout diameter, saturation flow, etc. Traffic-related parameters are generally derived according to the volume moves for different directions (through passing, right turn, left turn) and their average percentages. Passenger car equivalent (PCE) volumes are obtained using the coefficients suggested in the Highway Capacity Manual (HCM) 2010 [36]. The geometric layout of intersections is also considered in detail with the lane width and number, existence of turning bays and medians, distances between stop lines, etc. Control-related characteristics are generally based on signalization such as average green time and their percentages for 
each movement, number of phases, etc. The critical components in the immediate surrounding of each intersection are also described. In particular, the existence, number and distance of close intersections, and bus stops are indexed. As stated in HCM 2010, transit buses that stop for picking up or discharging passengers within $75 \mathrm{~m}$ of the stop line, block the traffic flow. Thus, the number and distance of upstream and downstream bus stops within $75 \mathrm{~m}$ of the stop line are indexed. Furthermore, the number of upstream and downstream intersections within $400 \mathrm{~m}$ of the stop line is considered during the modeling process by considering a $50 \mathrm{~km} / \mathrm{h}$ progressive speed for urban areas, where the traffic volumes are spread over several streets [37]. The mentioned parameters may be correlated with the intersection performance results and thus the relation between performance and characteristics may be established. Hence, policy makers may use those results for decision making and scenario generation processes of transportation planning at low levels.

\section{Step 1: Analysis and indexing of current intersections characteristics}

Step 2: Correlation analysis by using MARS

\section{Step 3: Obtaining} paradigms and strategies

Step 4: Generation of proposals and verification

Conclusions
Obtaining Intersection Data to Generate Correlation Parameters

- Describing and indexing of intersection features

- Performance analysis using microsimulation

\section{Setup Model}

- MARS model construction using Matlab functions

- Convergence of the models for eight different intersection performance indicator as dependent variables

- Interpretation of results

\begin{tabular}{|c|}
\hline$\downarrow$ \\
\hline $\begin{array}{l}\text { Generation of Parameters } \\
\text { - Obtaining parameters for scenario generation process } \\
\text { - Construction of theory and proposition }\end{array}$ \\
\hline$\downarrow$ \\
\hline $\begin{array}{l}\text { - Generation of a new scenario with obtained strategies } \\
\text { - Testing offered scenario with VISSIM traffic simulation } \\
\text { software } \\
\text { - Obtaining intersection performance results } \\
\text { - Comparison of base case and scenario results }\end{array}$ \\
\hline$\downarrow$ \\
\hline GENERAL CONSIDERATION \\
\hline
\end{tabular}

Fig. 1 - Flowchart of the traffic improvement stepwise paradigm

At the second stage of Step 1 in the stepwise paradigm, intersection performances are obtained using microsimulations. The VISSIM traffic simulation software is preferred for the study. It is utilized for visual analysis, and to measure the overall intersection performance. VISSIM was originally developed at the University of Karlsruhe, Germany. VISSIM may be used to analyze traffic and transit operations, traffic composition, bus stops, traffic signals, 
and evaluating different alternatives under various scenarios. It is a time-step, micro and behavior-based simulation model, which is developed to model traffic operations and analyze traffic performance. The simulation necessitates the input parameters like the geometry of traffic lanes, vehicle composition, speed, traffic volumes and movements at each intersection leg, vehicle routes in the intersection and conflict areas. The measurement parameters are the average delay time per vehicle (s), average speed $(\mathrm{km} / \mathrm{h})$, average number of stops per vehicles, average stopped delay per vehicle (s), total delay time (h), number of stops, total stopped delay (h), and total travel time (h). The mentioned software is a microscopic multimodal traffic flow simulation software package developed by PTV Planung Transport Verkehr AG in Karlsruhe [38].

Step 2; consists of a correlation analysis using the MARS approach. MARS is a multivariate nonparametric and nonlinear regression method, introduced by Friedman [39, 40]. The model consists of spline basis functions, where the basis functions and the parameters associated with each one (product degree and knot locations) are automatically determined by the data. This procedure is motivated by the recursive partitioning approach to regression and shares its attractive properties. It has more power and flexibility to model relationships that are nearly additive or involve interactions. Additionally, the model can be represented in a form that separately identifies the additive contributions and those associated with different multivariable interactions [39].

Because of the promising prediction power and interpretation simplicity of the MARS method, it is preferred in novel models, specifically where the nonlinearity between predictors and response are under question. Unlike other prediction models, a prior assumption for the relationship between dependent and independent variables is not required. Additionally, MARS is not a black-box model as much as the other nonlinear prediction techniques, e.g., artificial neural networks, fuzzy-logic, etc. because it provides an interpretable equation that includes coefficients according to the intervals produced by the model structure [35].

In recent years, transportation investigations use the MARS method in many studies such as accident analysis [41-43] and air passenger demand forecasting [34]. Although the application of MARS is limited in traffic engineering, the capability and interpretability of this approach is clearly introduced especially in traffic flow prediction [44, 45]. In these studies, short-term traffic flow prediction on interstate freeway segments is performed by considering spatio-temporal effects in the MARS method, and its superior prediction accuracy is revealed by comparing with many other advanced modeling techniques such as the parametric model autoregressive integrated moving averaging (ARIMA) and the kernel method support vector regression. This encourages the use of MARS in intersection-related analyses where multiple varieties of short run affects are under question.

In the MARS method, the relation between dependent and independent variables is described in intervals by piecewise regression functions. The term "piecewise" means that MARS divides the space of predictors into multiple knots and subsequently fits a spline function between them [42]. The general MARS function can be expressed using the following equation (1): 
Table 1a - List of explanatory (1-55) variables examined in MARS models.

\begin{tabular}{|c|c|c|c|}
\hline No & Variable Name & Short Name & Description \\
\hline 1 & Intersection control type & Cont & 1: signalized, 0 : unsignalized \\
\hline 2 & Intersection geometry type & Geo & 1: roundabout, 0 : others \\
\hline 3 & Cycle time* & Cyc & If the intersection is signalized (sec) \\
\hline 4 & Number of phases* & No.phases & If the intersection is signalized \\
\hline 5 & Number of legs & No.legs & \\
\hline 6 & Number of entering flows & No.enter & \\
\hline 7 & Intersection dimension in East-West direction & Dim_EW & Distance between E-W bound stop lines (m) \\
\hline 8 & Intersection dimension in North-South direction & Dim_NS & Distance between N-S bound stop lines (m) \\
\hline 9 & Existance of close intersection & Ex_close & yes: 1 , no:0 (closer than $400 \mathrm{~m})$ \\
\hline 10 & Number of close intersections & No.close & If Ex_close is 1 \\
\hline 11 & Number of left-turn moves with turning bay & No.LT_bay & \\
\hline 12 & Number of left-turn moves without turning bay & No.LT_nobay & \\
\hline 13 & Number of enters in which left-turns do not exist & No.noLT & \\
\hline 14 & Number of right-turn moves with turning bay & No.RT_bay & \\
\hline 15 & Number of right-turn moves without turning bay & No.RT_nobay & \\
\hline 16 & Number of enters in which right-turns do not exist & No.noRT & \\
\hline 17 & Number of legs with median (central refuge) & No.Med & \\
\hline 18 & Number of legs without median (central refuge) & No.noMed & \\
\hline 19 & Total number of enter lanes & No.EntLanes & \\
\hline 20 & Total number of exit lanes & No.ExtLanes & \\
\hline 21 & Average number of lanes per leg & Lane/Leg & \\
\hline 22 & Difference between the numbers of enter and exit lanes & Ent-Ext_lanes & No of enter lanes minus no of exit lanes \\
\hline 23 & Existance of close bus stops at enter flows & BusStop_Ent & 1:yes, 0: no (closer than 75 m) (HCM 2010) \\
\hline 24 & Average distance of close bus stops at enter flows & Dist_BS_Ent & If BusStop is 1 \\
\hline 25 & Number of close bus stops at left turns of exit flows & No.BS_Ext_LT & \\
\hline 26 & Number of close bus stops at through passing exit flows & No.BS_Ext_Str & \\
\hline 27 & Number of close bus stops at right turns of exit flows & No.BS_Ext_RT & \\
\hline 28 & Average distance of close bus stops at left turns of exit flows & Dist_BS_Ext_LT & If No.BS_Ext_LT is at least 1 \\
\hline 29 & Average distance of close bus stops at through passing exit flows & Dist_BS_Ext_Str & No.BS_Ext_Str is at least 1 \\
\hline 30 & Average distance of close bus stops at right turns of exit flows & Dist_BS_Ext_RT & No.BS_Ext_RT is at least 1 \\
\hline 31 & Average lane width & LaneWidth & $(\mathrm{m})$ \\
\hline 32 & Roundabout diameter & RA_dia & If the intersection is roundabout $(\mathrm{m})$ \\
\hline 33 & Cycling lane number & RA_no.lane & If the intersection is roundabout \\
\hline 34 & Average width of approach median & RA_appr & If the intersection is roundabout (m) \\
\hline 35 & Average green time for through passing flow* & GT_Thr & $(\mathrm{sec})$ \\
\hline 36 & Average green time for right turn flow* & GT_RT & $(\mathrm{sec})$ \\
\hline 37 & Average green time for left turn flow* & GT_LT & $(\mathrm{sec})$ \\
\hline 38 & Average green to cycle ratio for through passing flow* & $\mathrm{G} / \mathrm{C}_{-} \mathrm{Thr}$ & \\
\hline 39 & Average green to cycle ratio for right turn flow* & $\mathrm{G} / \mathrm{C}_{-} \mathrm{RT}$ & \\
\hline 40 & Average green to cycle ratio for left turn flow* & $\mathrm{G} / \mathrm{C} \_\mathrm{LT}$ & \\
\hline 41 & Average saturated flow of enter legs* & Sat.Flow & (veh./hour) \\
\hline 42 & Entering passenger car volume & $\mathrm{Vpc}$ & (veh./hour) \\
\hline 43 & Entering heavy vehicle volume & Vhv & (veh./hour) \\
\hline 44 & Entering total volume & Vtot & (veh./hour) \\
\hline 45 & Heavy vehicle ratio & HVR & \\
\hline 46 & Entering passenger car volume per lane & VperLpc & \\
\hline 47 & Entering heavy vehicle volume per lane & VperLhv & \\
\hline 48 & Entering total volume per lane & VperLtot & \\
\hline 49 & Average of leg based heavy vehicle ratio & HVRleg & \\
\hline 50 & Average of leg based saturation ratios & SatRat & \\
\hline 51 & Through passing passenger car volume & Vpc_Thr & (veh./hour) \\
\hline 52 & Through passing heavy vehicle volume & Vhv_Thr & (veh./hour) \\
\hline 53 & Through passing passenger car equivalent (PCE) volume & Vpce_Thr & (pce/hour) \\
\hline 54 & Number of through passing flows & No.Thr & \\
\hline 55 & Ratio of through passing flow number to enter flow number & no. Rat Thr & \\
\hline
\end{tabular}


Table $1 b$ - List of explanatory (56-75) and dependent (P1-P8) variables examined in MARS models.

\begin{tabular}{|c|c|c|c|}
\hline No & Variable Name & Short Name & Description \\
\hline 56 & Average ratio of through passing over entering flow & AvRat Thr & \\
\hline 57 & Leg based average ratio of through passing over entering flow & AvRat_Leg_Thr & \\
\hline 58 & Right turn passenger car volume & Vpc_RT & (veh./hour) \\
\hline 59 & Right turn heavy vehicle volume & Vhv_RT & (veh./hour) \\
\hline 60 & Right turn PCE volume & Vpce RT & (pce/hour) \\
\hline 61 & Number of right turn flows & No.RT & \\
\hline 62 & Ratio of right turn flow number to enter flow number & no.Rat_RT & \\
\hline 63 & Average ratio of right turn over entering flow & AvRat_RT & \\
\hline 64 & Leg based average ratio of right turn over entering flow & AvRat_Leg_RT & \\
\hline 65 & Left turn passenger car volume & Vpc_LT & (veh./hour) \\
\hline 66 & Left turn heavy vehicle volume & Vhv_LT & (veh./hour) \\
\hline 67 & Left turn PCE volume & Vpce_LT & (pce/hour) \\
\hline 68 & Number of left turn flows & No.LT & \\
\hline 69 & Ratio of left turn flow number to enter flow number & no.Rat_LT & \\
\hline 70 & Average ratio of left turn over entering flow & AvRat_LT & \\
\hline 71 & Leg based average ratio of left turn over entering flow & AvRat_Leg_LT & \\
\hline 72 & Entering PCE volume & Vpce & (pce/hour) \\
\hline 73 & Average green time per entering vehicle for through passing flow* & GTr_Thr & $(\mathrm{sec} /(\mathrm{pce} /$ hour $))$ \\
\hline 74 & Average green time per entering vehicle for right turn flow* & GTr_RT & $(\mathrm{sec} /(\mathrm{pce} /$ hour$))$ \\
\hline 75 & Average green time per entering vehicle for left turn flow* & GTr LT & $(\mathrm{sec} /(\mathrm{pce} / \mathrm{hour}))$ \\
\hline P1 & Average delay time per vehicle & P1.DelpVeh & $(\mathrm{sec})$ \\
\hline $\mathbf{P 2}$ & Average speed & P2.AvSpeed & $(\mathrm{km} / \mathrm{h})$ \\
\hline P3 & Total delay time & P3.TotDelay & (hour) \\
\hline P4 & Total distance traveled & P4.TotDist & $(\mathrm{km})$ \\
\hline P5 & Number of stops & P5.No.Stops & \\
\hline P6 & Number of vehicles that have left the network & P6.No.VehLeft & \\
\hline P7 & Total travel time & P7.Tot_TrlTime & (hour) \\
\hline P8 & Average travel time per vehicle & P8.Ave_TrlTime & (hour/veh.) \\
\hline
\end{tabular}

* For signalized intersections

$y=b_{o}+\sum_{m=1}^{M} b_{m} B_{m}(x)$

where $y$ is the dependent variable; $x$ is the explanatory variable; $b_{o}$ and $b_{m}$ are the estimated coefficients to yield the best fit of data; $M$ is the number of basis functions included into the model. $B_{m}(x)$ is the $m^{\text {th }}$ basis function, which can be either a single function or the product of two or more functions for different explanatory variables $[34,46]$. The piecewise-linear form of the basis function is shown below:

$B_{m}(x)=\prod_{k=1}^{k_{m}}\left[S_{k m}\left(X_{v(k, m)}-t_{k, m}\right)\right]$ 
In the equation, $k m$ is the number of knots, $S_{k m}$ can be either 1 or -1 to indicate the right/left regions of the associated step function, $v(k, m)$ is the label of the explanatory variable, and $t_{k, m}$ is the knot location [34]. A cubic version of this piecewise-linear form also exists for the basis functions, in which a power function is applied for each multiplication segment. However, the piecewise-linear form is preferred in this study to provide simple interpretability.

In the modeling process, two primary steps are applied. The first step is the "construction where basis functions are added to the model using a forward stepwise procedure." The predictors and their knot locations (thresholds) that contribute to the model are defined. In the second step, or the "pruning phase," the basis functions with the least contribution are eliminated using backward deletion. To avoid overfitting, a generalized cross-validation statistic is typically used, where a penalty for model complexity is accounted for [42]. The Generalized Cross-Validation (GCV) criterion is estimated using the following equation:

$$
G C V(M)=\frac{1}{N} \frac{\sum_{i=1}^{N}\left(y_{i}-\hat{y}\right)^{2}}{(1-C(\tilde{M}) / N)^{2}}
$$

where $N$ is the number of observations; $y_{i}$ is the response for observation $i ; \hat{y}$ is the predicted response for observation $i ; C(\tilde{M})$ is the complexity penalty factor.

Step 3; obtains the process for paradigms and strategies. It consists of the generation of design parameters. In this section, the relationship between intersection characteristics and intersection performance results is determined. To obtain the most effective intersection properties that should be considered as the top priority, explanatory variables are analyzed in terms of occurrence frequency and relative importance in the MARS predictions of intersection performance indicators.

Because of the mentioned relationship, the intersection characteristics to be evaluated during the scenario production phase and the intersection characteristics that are meaningful in the model are determined. Hence, the theory of the proposition to be developed has been determined. The most related variables in terms of performance indicators have been chosen to be utilized in the determination process.

Step 4; consists of the generation of design proposals and design verification. At this stage, the design parameters obtained are evaluated and the intervening intersections and method of intervention are determined. The strategies for the selected intersection are determined and a scenario is generated using the determined parameters. The intersection design is generated towards the scenario, and the mentioned intersection design is simulated with the equal traffic demand. Subsequently, the intersection performance indicators are obtained for the designed case, and the intersection design parameters are determined by comparing with the base case intersection performance indicators. 


\subsection{Study Area}

Tekirdağ is a metropolitan seaport that attracts attention oflarge organized industrial zones. The city has significant tourism investments and several advantages due to its location. Tekirda $\breve{g}$ is near Istanbul and it is one of the most notable cities in the Marmara region [47]. Tekirdağ has 11 counties, and the most important ones are Süleymanpaşa, Çorlu, and Çerkezköy in terms of economy andpopulation. Çorlu and Çerkezköy lead the industrial sector, while Süleymanpaşa leads the service sector.

The macroform of Süleymanpaşa is adjacent to the seaside. It has a linear urban development between the East-West axis. A belt highway in the north of the city is located as an artificial threshold. The population of the county is 176,848 . Çorlu is the largest county of Tekirdağ, and it is $38 \mathrm{~km}$ away from the city center. It is one of Turkey's largest counties. Rapid urbanization, intense industrialization, and outside-in migration are the significant problems of the county. The population of the county is 273,362 , and it is at the intersection point of large-scaled transportation corridors. Çerkezköy has an increasing population, and it has the highest population density. Many access opportunities to the city exist in terms of transportation modes. The county containing industrial zones has a population of 146,319. Malkara is another significant settlement and it has four intersections with traffic surveys. Locations of four counties are given in Fig. 2.

Traffic surveys and counts are conducted by drones and subsequently counted in the office environment. Counts are conducted for evening and morning peak hours. However, in the study only the morning peak hour count results are evaluated. Traffic counts were performed when the schools were open, and the actual traffic pattern was observed. Counts are conducted in categories such as cars, minibuses, trucks, and buses. The speed and behavior patterns are also observed. The traffic characteristics of the settlements in Tekirdağ are similar to each other. In fact, they are similar to the traffic characteristics of the other medium-sized cities of Turkey. Heavy vehicle traffic and urban public transport traffic constitute only a fraction of the overall traffic. Private car use is relatively high in the overall traffic. Traffic congestion is observed at peak hours in specific central regions. The transportation infrastructure shows that the city is located at the seashore, and some traffic axes are not accessible.

\section{ANALYSIS}

\subsection{Indexing of intersection properties}

Traffic surveys and simulations are conducted for 64 intersections. The simulations have been conducted using the VISSIM traffic software. In the calibration section, the vehicle speed and behavior pattern are iteratively updated until the number of vehicles passing through the intersection arms are equalized to the traffic counts. The obtained performance results are generated by a network performance analysis and supported by visual captures. Performance indicators are calculated for the base case. More than $75 \%$ of these intersections are located in four sites (Çerkezköy, Çorlu, Malkara, and Süleymanpaşa). Others are scattered in different districts and on intercity roads, including roundabouts, and intersections with signalized and unsignalized intersections. Fig. 3 shows the locations of the intersections in Çerkezköy, Çorlu, Malkara, and Süleymanpaşa. 


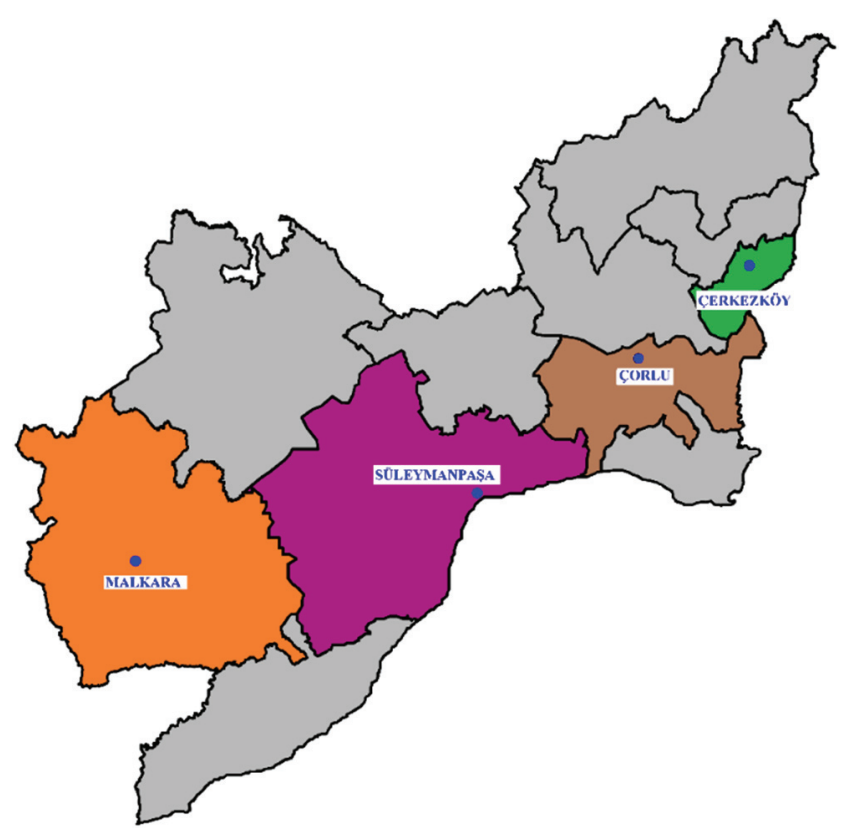

Fig. 2 - Locations of Çerkezköy, Çorlu, Malkara, and Süleymanpaşa
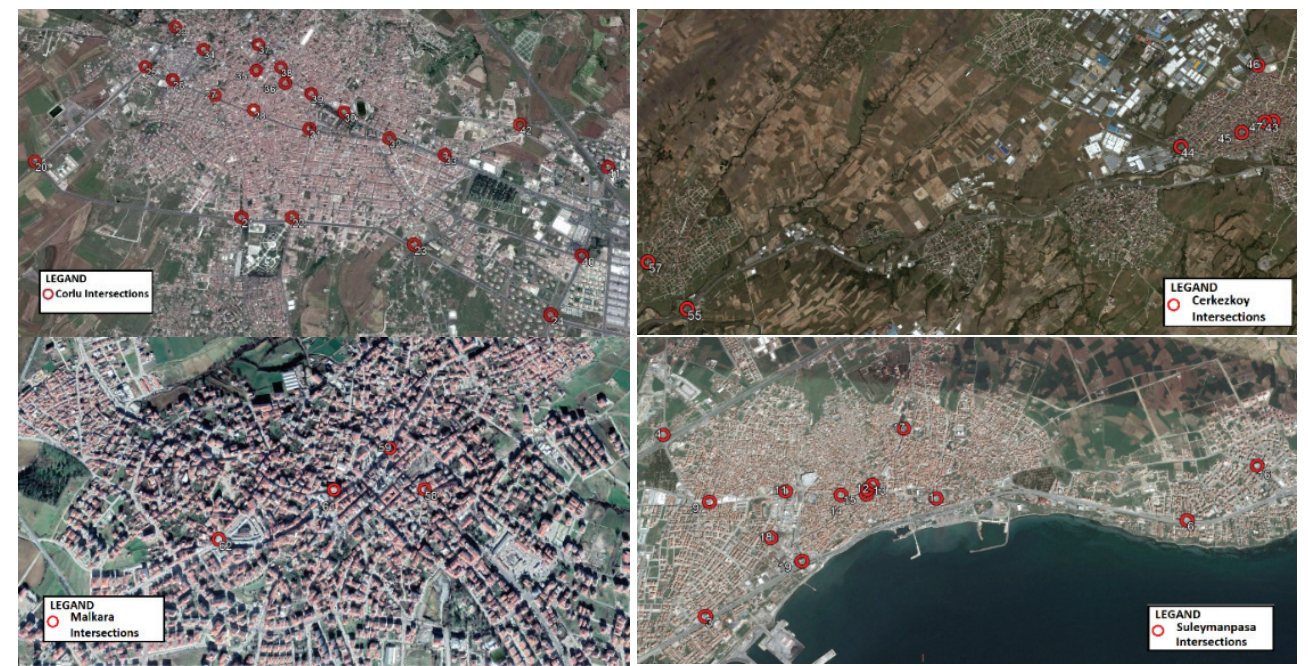

Fig. 3 - Locations of intersections in Çerkezköy, Çorlu, Malkara, and Süleymanpaşa

In this study, we performed a calibration process based on field volumes and number of vehicles that have left the network through 64 intersections. Comparison of field and 
simulation volumes are given in Fig. 4. As can be seen in the figure, R-squared value is about 0.89 which represents smaller differences between the field data and the fitted values.

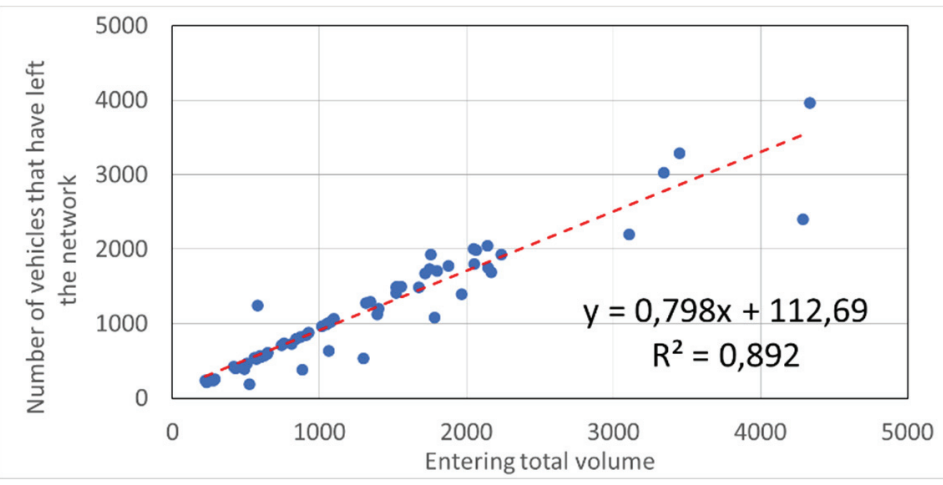

Fig. 4 - Comparison of field and simulation volumes

\subsection{MARS model results}

The derived intersection characteristics based on geometry, control, and traffic, are examined to estimate eight different intersection performance indicators using the MARS method. In MARS modeling, the functions developed by Jekabsons [48] based on Friedman's method $[39,40]$ in Matlab programming language are utilized with some modifications according to the scope of the study.

As the first step, data standardization process is added to generated codes. Before performing a MARS model, it is recommended to pre-scale the explanatory and dependent variables to the $0-1$ interval [39]. Hence, the transformation equation used is shown below:

$X_{i}^{s}=\left(X_{i}^{o}-X_{\min }^{o}\right) /\left(X_{\max }^{o}-X_{\min }^{o}\right)$

where $X_{i}^{s}$ is the standardized value of the $i^{\text {th }}$ observation of the explanatory variable, $X_{i}^{o}$ is the observed value, and $X_{\min }^{o}$ and $X_{\max }^{o}$ are the minimum and maximum values of the related observations, respectively.

For the second step of the code modification, basic functions of Jekabsons [48] are combined to construct, converge and evaluate MARS models. The three main steps used in the modeling process are creating structure of model configuration parameters, building MARS model with dependent and independent variables, performing ANOVA decomposition and variable importance assessment. Also a conditional loop is constructed for repeating the process until obtaining a model with significant dependent variables by comparing relative importance values. The relative importance of a variable is defined as the square root of the GCV of the model with all basis functions involving that variable removed, minus the square root of the GCV score of the corresponding full model, scaled such that the relative importance of the most important variable has a value of $100[35,40]$. 
In the initial modeling stage, the maximum number of basis functions is limited to 20 in the piecewise linear form, and all of the 75 explanatory variables (intersection characteristics) are included. After the first convergence of the MARS model, the explanatory variables with relative importance smaller than 5\% are eliminated, and the model is converged again. This process is repeated until all of the remaining explanatory variables have a relative importance of over $5 \%$.

For clarifying the estimation capability of the models, in addition to the MARS model specific indicators $\left(\mathrm{GCV}, \mathrm{R}^{2} \mathrm{GCV}\right)$, the calculation of some well-accepted statistics that are based on the prediction residuals and widely used for comparing the performance in nonlinear predictions are attached to Jekabsons' functions [48]: root mean square error (RMSE), efficiency factor $(\mathrm{EF})$, post regression statistics for observed and predicted values (slope $(\mathrm{m})$, intercept (b), and coefficient of correlation (r)), and discrepancy ratio percentages (DRP) [49]. DR percentages are provided for both the $10 \%$ and $25 \%$ discrepancies (see Table 2 ). Besides, the predictive power of the models are examined by using training and testing stages. For this purpose, randomly selected 42 of 64 intersection data are implemented for training and the generated models are tested by using the remaining 22 intersection data.

As shown in Table 2, all the intersection performance indicators have been considerably predicted by the explanatory variables. All of the models exhibit $\mathrm{R}_{\mathrm{GCV}}^{2}$ values over 0.80 , and efficiency factors over 0.85 . Generally, the MARS model appears to be useful in the estimation of any intersection performance according to the all data-based trainings. The most distinctive differences between the prediction capabilities are obtained by comparing the post regression and discrepancy statistics. When the discrepancy is considered as $25 \%$ for all data models, the average speed is shown to be estimated properly for all of the observations. The number of vehicles that have left the network, average travel time per vehicle, total distance travelled, and total travel time also indicate high proper estimation percentages, while the others present considerable percentages for high predictions. When the post regression statistics are compared, the prominent performances can be found as the average speed, total delay time, number of stops, and total travel time, in which the coefficient of correlation $(\mathrm{r})$ is approximately 0.98 .

Although convergence performances are increased with randomly divided data, prediction performances with testing set are generally decreased (compared with all data) as expected. According to F-test probability values which should be smaller than 0.05 for a significant performance, average speed (P2), total delay time (P3), number of stops (P5) number of vehicles that have left the network (P6) and average travel time per vehicle (P8) models have high predictive power with testing data. These models still have coefficient of determination (R-squared) and efficiency factors over 0.65. Consequently, it can be said that MARS modeling approach shows prominent estimation capability for these five performance indicators.

According to $\mathrm{R}_{\mathrm{GCV}}^{2}$ statistics which is the main indicator of MARS modeling, the performance indicators average speed (P2), number of stops (P5) and total travel time (P7) are found to be the most predictable indicators. Since total travel time is strongly related with the number of vehicles using the intersections, it is preferred to focus on average travel time per vehicle (P8). Consequently, for the brevity of the study, three of the indicators were selected for the comprehensive analysis: average speed (P2), number of stops (P5), and average travel time per vehicle (P8). 
Table 2 - General prediction performances of MARS models for eight different intersection performance indicators

\begin{tabular}{|c|c|c|c|c|c|c|c|c|c|c|}
\hline \multirow{3}{*}{$\begin{array}{l}\text { Intersection } \\
\text { Performance } \\
\text { Indicator }\end{array}$} & & No: & P1 & P2 & P3 & $\mathrm{P} 4$ & P5 & $\mathrm{P} 6$ & $\mathrm{P} 7$ & P8 \\
\hline & & Descpriction: & $\begin{array}{c}\text { Average } \\
\text { delay time } \\
\text { per vehicle }\end{array}$ & $\begin{array}{c}\text { Average } \\
\text { speed }\end{array}$ & $\begin{array}{c}\text { Total delay } \\
\text { time }\end{array}$ & $\begin{array}{l}\text { Total } \\
\text { distance } \\
\text { traveled }\end{array}$ & $\begin{array}{c}\text { Number of } \\
\text { stops }\end{array}$ & $\begin{array}{c}\text { Number of } \\
\text { vehicles that } \\
\text { have left the } \\
\text { network }\end{array}$ & $\begin{array}{l}\text { Total travel } \\
\text { time }\end{array}$ & $\begin{array}{l}\text { Average } \\
\text { travel time } \\
\text { per vehicle }\end{array}$ \\
\hline & & Short name: & DelpVeh & AvSpeed & TotDelay & TotDist & No.Stops & No.VehLeft & Tot_TrITime & Ave_TrlTime \\
\hline \multirow{5}{*}{$\begin{array}{l}\text { MARS model } \\
\text { convergence }\end{array}$} & \multirow{2}{*}{$\begin{array}{l}\text { all data } \\
\text { (64 intersections) }\end{array}$} & GCV & 0.01001 & 0.00819 & 0.00586 & 0.00819 & 0.00693 & 0.00346 & 0.00326 & 0.00780 \\
\hline & & $\mathrm{R}_{\mathrm{GCV}}^{2}$ & 0.880 & 0.924 & 0.914 & 0.789 & 0.924 & 0.919 & 0.935 & 0.819 \\
\hline & \multirow{2}{*}{$\begin{array}{l}\text { training data } \\
\text { (42 intersections) }\end{array}$} & $\mathrm{GCV}$ & 0.00349 & 0.00665 & 0.00556 & 0.00600 & 0.00491 & 0.00178 & 0.00176 & 0.00667 \\
\hline & & $\mathrm{R}_{\mathrm{GCV}}^{2}$ & 0.949 & 0.930 & 0.904 & 0.860 & 0.938 & 0.960 & 0.961 & 0.828 \\
\hline & \multicolumn{2}{|c|}{ Number of basis functions } & 11 & 9 & 11 & 8 & 11 & 4 & 10 & 10 \\
\hline \multirow{12}{*}{$\begin{array}{l}\text { General prediction } \\
\text { performances }\end{array}$} & \multirow{6}{*}{$\begin{array}{l}\text { all data } \\
\text { (64 intersections) }\end{array}$} & $\mathrm{R}$ & 0.972 & 0.979 & 0.980 & 0.934 & 0.982 & 0.966 & 0.983 & 0.953 \\
\hline & & R-squared & 0.944 & 0.958 & 0.960 & 0.872 & 0.964 & 0.934 & 0.967 & 0.908 \\
\hline & & F & 89.467 & 155.436 & 126.632 & 54.610 & 143.531 & 281.214 & 173.723 & 59.032 \\
\hline & & $\mathrm{Pf}$ & : & 0 & 0 & 0 & 0 & 0 & 0 & 0 \\
\hline & & RMSE & 0.067 & 0.066 & 0.051 & 0.069 & 0.056 & 0.052 & 0.040 & 0.062 \\
\hline & & $\mathrm{EF}$ & 0.944 & 0.958 & 0.960 & 0.872 & 0.964 & 0.934 & 0.967 & 0.908 \\
\hline & \multirow{6}{*}{$\begin{array}{l}\text { testing data } \\
(22 \text { intersections) }\end{array}$} & $\mathrm{R}$ & 0.702 & 0.865 & 0.803 & 0.581 & 0.894 & 0.830 & 0.703 & 0.834 \\
\hline & & R-squared & 0.493 & 0.747 & 0.645 & 0.337 & 0.800 & 0.688 & 0.494 & 0.695 \\
\hline & & F & 1.582 & 9.467 & 5.807 & 3.053 & 6.498 & 5.525 & 1.074 & 13.673 \\
\hline & & $\mathrm{Pf}$ & 0.22188 & 0.00024 & 0.00304 & 0.05507 & 0.00164 & 0.00338 & 0.45126 & 0.00007 \\
\hline & & RMSE & 0.230 & 0.176 & 0.170 & 0.144 & 0.144 & 0.110 & 0.168 & 0.140 \\
\hline & & $\mathrm{EF}$ & 0.493 & 0.747 & 0.645 & 0.337 & 0.800 & 0.688 & 0.494 & 0.695 \\
\hline \multirow{6}{*}{$\begin{array}{l}\text { Post regression } \\
\text { statistics }\end{array}$} & \multirow{3}{*}{$\begin{array}{l}\text { all data } \\
\text { (64 intersections) }\end{array}$} & $\mathrm{m}$ & 0.944 & 0.958 & 0.960 & 0.872 & 0.964 & 0.934 & 0.967 & 0.908 \\
\hline & & $\mathrm{b}$ & 0.013 & 0.024 & 0.007 & 0.025 & 0.008 & 0.017 & 0.006 & 0.027 \\
\hline & & $\mathrm{r}$ & 0.972 & 0.979 & 0.980 & 0.934 & 0.982 & 0.966 & 0.983 & 0.953 \\
\hline & \multirow{3}{*}{$\begin{array}{l}\text { testing data } \\
(22 \text { intersections) }\end{array}$} & $\mathrm{m}$ & 0.579 & 0.780 & 1.046 & 1.099 & 0.995 & 1.277 & 1.212 & 0.515 \\
\hline & & $\mathrm{b}$ & 0.038 & 0.176 & -0.004 & 0.014 & 0.007 & -0.042 & -0.003 & 0.105 \\
\hline & & $\mathrm{r}$ & 0.754 & 0.885 & 0.870 & 0.814 & 0.912 & 0.943 & 0.881 & 0.930 \\
\hline \multirow{6}{*}{$\begin{array}{l}\text { Discrepancy ratio } \\
\text { percentages } \\
\text { (10\% discrepancy) }\end{array}$} & \multirow{3}{*}{$\begin{array}{l}\text { all data } \\
\text { (64 intersections) }\end{array}$} & $\mathrm{DRP}_{\text {low }}$ & 14.06 & 3.13 & 15.63 & 21.88 & 14.06 & 1.56 & 25.00 & 14.06 \\
\hline & & $\mathrm{DRP}_{\text {proper }}$ & 37.50 & 87.50 & 37.50 & 42.19 & 35.94 & 89.06 & 45.31 & 70.31 \\
\hline & & $\mathrm{DRP}_{\text {high }}$ & 48.44 & 9.38 & 46.88 & 35.94 & 50.00 & 9.38 & 29.69 & 15.63 \\
\hline & \multirow{3}{*}{$\begin{array}{l}\text { testing data } \\
\text { (22 intersections) }\end{array}$} & $\mathrm{DRP}_{\text {low }}$ & 72.73 & 13.64 & 22.73 & 36.36 & 9.09 & 22.73 & 45.45 & 27.27 \\
\hline & & $\mathrm{DRP}_{\text {proper }}$ & 9.09 & 50.00 & 13.64 & 9.09 & 27.27 & 50.00 & 9.09 & 45.45 \\
\hline & & $\mathrm{DRP}_{\text {high }}$ & 18.18 & 36.36 & 63.64 & 54.55 & 63.64 & 27.27 & 45.45 & 27.27 \\
\hline \multirow{6}{*}{$\begin{array}{l}\text { Discrepancy ratio } \\
\text { percentages } \\
\text { (25\% discrepancy) }\end{array}$} & \multirow{3}{*}{$\begin{array}{l}\text { all data } \\
\text { (64 intersections) }\end{array}$} & $\mathrm{DRP}_{\text {low }}$ & 9.38 & 0.00 & 10.94 & 4.69 & 4.69 & 1.56 & 14.06 & 4.69 \\
\hline & & $\mathrm{DRP}_{\text {proper }}$ & 51.56 & 100.00 & 48.44 & 87.50 & 56.25 & 93.75 & 76.56 & 92.19 \\
\hline & & $\mathrm{DRP}_{\text {high }}$ & 39.06 & 0.00 & 40.63 & 7.81 & 39.06 & 4.69 & 9.38 & 3.13 \\
\hline & \multirow{3}{*}{$\begin{array}{l}\text { testing data } \\
\text { ( } 22 \text { intersections) }\end{array}$} & $\mathrm{DRP}_{\text {low }}$ & 59.09 & 0.00 & 4.55 & 13.64 & 4.55 & 0.00 & 22.73 & 4.55 \\
\hline & & $\mathrm{DRP}_{\text {proper }}$ & 31.82 & 86.36 & 59.09 & 59.09 & 45.45 & 100.00 & 50.00 & 90.91 \\
\hline & & $\mathrm{DRP}_{\text {high }}$ & 9.09 & 13.64 & 36.36 & 27.27 & 50.00 & 0.00 & 27.27 & 4.55 \\
\hline
\end{tabular}




\subsubsection{Average Speed (P2)}

A high average speed at an intersection can indicate that queuing and delays are at the minimum, and traffic flows without any considerable interruptions. In the MARS models, the average speed provides a successive estimation of the intersection performance. The model converges with $0.00819 \mathrm{GCV}$ value, and nine basis functions (including intercept). Equation 5 shows the final form of the MARS estimation function. The standardized forms of the basis functions are also shown in Table 3. As shown in the equation, the number of phases (No.phases), cycle time (Cyc), entering heavy vehicle volume (Vhv), and entering total volume per lane (VperLtot) are the effective variables in the prediction. According to Eq. 5, No.phases in the MARS prediction indicates that if the number of phases is under four, it increases the average speed by $1.32 \mathrm{~km} / \mathrm{h}$ for every decreasing number. The critical threshold for Vhv is found to be 714.6 and this variable has two different basis functions. Each additional heavy vehicle over this threshold decreases its average speed by $0.579 \mathrm{~km} / \mathrm{h}$, and each vehicle decreasing under this rate also increases by $0.479 \mathrm{~km} / \mathrm{h}$. This means that the number of heavy vehicles influences significantly on the average speed. Cycle time values of under $88.956 \mathrm{~s}$ present an adverse effect with a -0.775 coefficient. The VperLtot variable has a more complicated effect on the average speed than the other explanatory variables, because of four different basis functions and several threshold values. It can be inferred that a VperLtot of over 151.715 negatively affects the average speed, while it can increase it for values under $138.275 \mathrm{veh} / \mathrm{h} / \mathrm{lane}$. A sensitivity analysis, which will be discussed in the next paragraphs, can be more expressive for this type of variables.

$$
\begin{aligned}
& \text { P2.AvSpeed }=31.556+1.32 * \max (0,4-\text { No.phases })-0.579 * \max (0, \mathrm{Vhv}-714.6) \\
& +0.479 * \max (0,714.6-\mathrm{Vhv})-2.09 * \max (0,310.615-\text { VperLtot }) \\
& -0.775 * \max (0,88.956-\mathrm{Cyc})+2.23 * \max (0, \mathrm{VperLtot}-238.675) \\
& -2.98 * \max (0, \text { VperLtot }-151.715)+1.99 * \max (0,138.275-\text { VperLtot })
\end{aligned}
$$

Table 3 - Basis function coefficient statistics of MARS model for P2.AvSpeed

\begin{tabular}{llrrrr}
\hline No & Basis function & Coefficient & Standard error & t statistics & P-value \\
\hline BF0 & Intercept & 0.586 & 0.118 & 4.950 & 0 \\
BF1 & $\max (0,0.8$ - No.phases $)$ & 1.324 & 0.152 & 8.710 & 0 \\
BF2 & $\max (0$, Vhv - 0.636) & -0.579 & 0.204 & -2.833 & 0.0064 \\
BF3 & $\max (0,0.636$ - Vhv) & 0.479 & 0.092 & 5.190 & 0 \\
BF4 & $\max (0,0.337$ - VperLtot $)$ & -2.094 & 0.480 & -4.367 & 0.0001 \\
BF5 & $\max (0,0.706$ - Cyc) & -0.775 & 0.164 & -4.733 & 0 \\
BF6 & $\max (0$, VperLtot - 0.246) & 2.234 & 0.790 & 2.829 & 0.0065 \\
BF7 & $\max (0$, VperLtot - 0.136) & -2.981 & 0.830 & -3.592 & 0.0007 \\
BF8 & $\max (0,0.119-$ VperLtot $)$ & 1.993 & 0.627 & 3.178 & 0.0024 \\
\hline
\end{tabular}


The relative importance of the variables in the model is shown in Table 4. The $\mathrm{R}^{2}{ }_{\mathrm{GCV}}$ values in the table show the prediction capability of the MARS model for the case of excluding the considered variable. It is clear that the most important variable in the model is the number of phases. The entering heavy vehicle volume follows this variable. Because limiting the number of heavy vehicles using an intersection is only possible with transportation network management, the number of phases may be considered for maintaining average speed performance.

The relative importance of each basis function in the model can be investigated using Table 3. Considerably small and zero values of probabilities $(\mathrm{P})$ of the thatistics show that every basis function is essential in the prediction of the average speed. When the absolute values of $t$ statistics are compared, BF1 that included No.phases appears to be the most effective basis function. BF3, the intercept, and BF5 follow BF1.

Table 4 - MARS model ANOVA for P2.AvSpeed model.

\begin{tabular}{crrrrrr}
\hline $\begin{array}{c}\text { ANOVA } \\
\text { function }\end{array}$ & $\begin{array}{r}\text { Basis functions } \\
\text { numbers }\end{array}$ & Variables & $\begin{array}{r}\text { Standard } \\
\text { deviation }\end{array}$ & GCV & $\mathrm{R}^{2} \mathrm{GCV}$ & $\begin{array}{r}\text { Relative } \\
\text { importance }\end{array}$ \\
\hline 1 & 5 & Cyc & 0.25596 & 0.01061 & 0.901 & 28.75 \\
2 & 1 & No.phases & 0.47400 & 0.01793 & 0.833 & 100.00 \\
3 & 2,3 & Vhv & 0.11558 & 0.01344 & 0.875 & 58.60 \\
4 & $4,6,7,8$ & VperLtot & 0.07731 & 0.01211 & 0.887 & 45.04 \\
\hline
\end{tabular}

Fig. 5 demonstrates a graphical sensitivity analysis of the average speed model. For obtaining each line of the figure, the model is simulated 401 times with a range of each considered model parameter between -2 and 2 times of its mean value of observations with 0.01 increment. At every 401 simulations of the considered parameter, the other model parameters are fixed at their mean observation values. Consequently, the corresponding proportional change in model predictions with respect to the model in which all of the model parameters are taken as mean are obtained. The horizontal axis shows the proportional change in each model parameter around the average of observations and the vertical axis indicates the corresponding proportional change in the average speed model. The complicated effect of VperLtot is clearer from the figure. The changes in slopes of the VperLtot line indicates several thresholds in the model. In general, this variable exhibits the largest adverse effect on the average speed performance, when its steepest average slope is considered. While a low Vhv increases the average speed as much as VperLtot, this cannot be assumed for high Vhv. Although the number of phases is the most important variable in the model, the sensitivity graph demonstrates a lower impact than the ones of VperLtot and Vhv. Additionally, the effect of No.phases diminishes over (approximately) a 0.4 increase. The cycle time also decreases the average speed for low ratios (according to the mean of observations); however, it is ineffective for high ratios. It is noteworthy that the sensitivity lines are related to the magnitude and sign of the explanatory variable coefficients. The coefficients may or may not relate to the significance of the explanatory variable in explaining the variance of the dependent variable. 


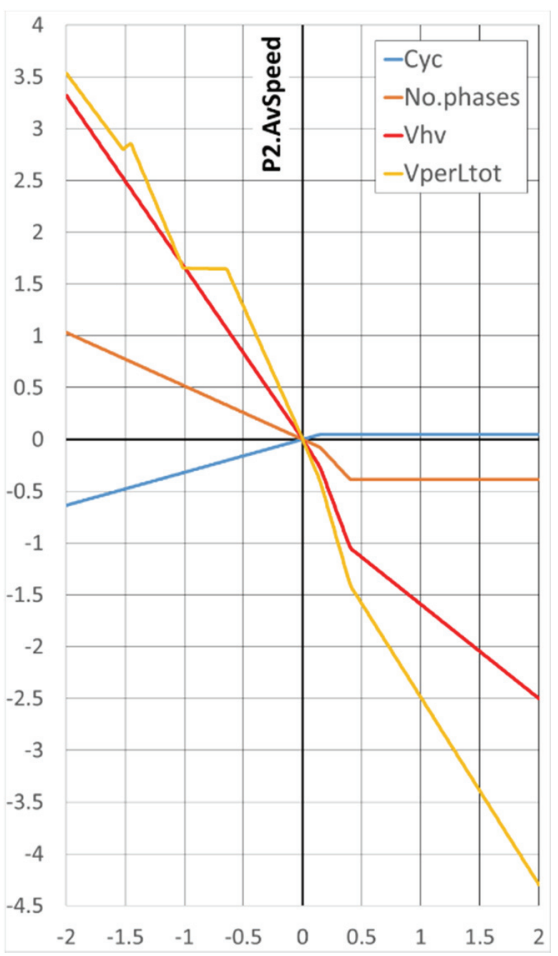

Fig. 5 - Sensitivity analysis for MARS variables in P2.AvSpeed model.

\subsubsection{Number of Stops (P5)}

The number of stops can be used as a measure of interruptions in traffic flows. The less number of stops means more fluent flows at the intersections. The MARS model of number of stops converges with $0.00693 \mathrm{GCV}$ and 11 basis functions. The final form of the basis functions and their standardized version are shown in Eq. 6 and Table 5, respectively. Seven different parameters are found to be significant in the prediction: average width of approach median of roundabout (RA_appr), entering heavy vehicle volume (Vhv), through passing passenger car equivalent volume (Vpce_Thr), leg-based average ratio of right turn over entering flow (AvRat_Leg_RT), left turning passenger car volume (Vpc_LT), entering passenger car equivalent volume (Vpce), and average green time per entering vehicle for right turn flow (GTr_RT). It can be inferred that the estimation of P5 is rather complicated and related with several parameters depending on vehicle movements, signalization and geometry. Vpce of over 1030 (approximately), and Vhv of over 296 appear to increase the number of stops as threshold values. Additionally, vehicle movements such as Vpc_LT of under 290, and Vpce Thr of under 410 cause a decreasing effect on this performance. Further, $14 \%$ is found to be the threshold for the right turn ratio with two basis functions. Unlike other variables, the roundabout approach width has a linear effect with 0.242 coefficient, implying that this width raises the number of stops in all conditions. Additionally, the average green time per right turning vehicle of over $0.679 \mathrm{~s}$ increases the stops. 


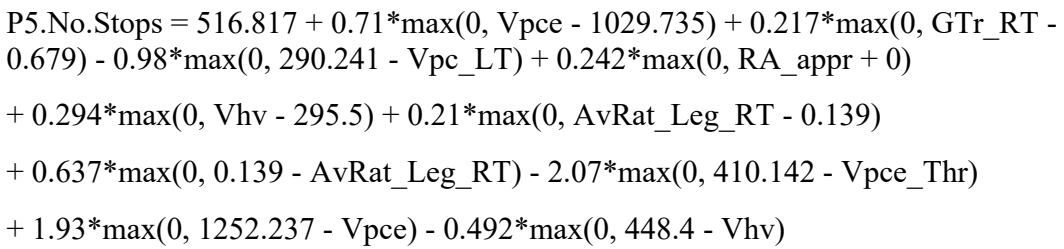

Table 5 shows that the basis functions including Vpce, Vpc_LT, and RA_appr variables are the most effective basis functions according to the $t$ statistics. Table $\overline{6}$ that includes the relative importance of each variable also shows similar results in the variable-based form. Although Vpc_LT includes only one basis function, it is the second important variable in the MARS model, and this proves the critical significance of left turns in the intersection performance. Fig. 6 demonstrates the sensitivity of the model for each variable, while the others are maintained in their average values. Interestingly, Vpce and GTr_RT show similar sensitivities. This may arise from the site-specific observation correlations of these parameters. Contrary to the regression model, the MARS model does not require multicollinearity analysis and thus the elimination of this type of correlations is simply a modeller preference. Some fluctuations are observed on the sensitivity for the low values of the AvRat_Leg_RT, Vpce, and GTr_RT variables. The emergence of these nonlinear differences is an important advantage of the MARS modeling approach. Although RA_appr is found to be the third most important variable according to the ANOVA statistics, it gives the lowest sensitivity when it is compared with the other variables. This may arise from the limited number of roundabouts and the small range of approach width observations.

Table 5 - Basis function coefficient statistics of MARS model for P5.No.Stops

\begin{tabular}{llrrrr}
\hline No & Basis function & Coefficient & Standard error & t statistics & P-value \\
\hline BF0 & Intercept & 0.101 & 0.033 & 3.046 & 0.0036 \\
BF1 & $\max (0$, Vpce - 0.155) & 0.711 & 0.072 & 9.922 & 0 \\
BF2 & $\max (0$, GTr_RT - 0.143) & 0.217 & 0.045 & 4.809 & 0 \\
BF3 & $\max (0,0.271$ - Vpc_LT $)$ & -0.980 & 0.115 & -8.521 & 0 \\
BF4 & $\max (0$, RA_appr + 0) & 0.242 & 0.034 & 7.156 & 0 \\
BF5 & $\max (0$, Vhv - 0.255) & 0.294 & 0.086 & 3.418 & 0.0012 \\
BF6 & $\max (0$, AvRat_Leg_RT - 0.227) & 0.210 & 0.052 & 4.011 & 0.0002 \\
BF7 & $\max (0,0.227$ - AvRat_Leg_RT) & 0.637 & 0.156 & 4.083 & 0.0002 \\
BF8 & $\max (0,0.0963$ - Vpce_Thr $)$ & -2.072 & 0.502 & -4.131 & 0.0001 \\
BF9 & $\max (0,0.201-$ Vpce $)$ & 1.926 & 0.309 & 6.241 & 0 \\
BF10 & $\max (0,0.394-$ Vhv $)$ & -0.492 & 0.163 & -3.030 & 0.0038 \\
\hline
\end{tabular}




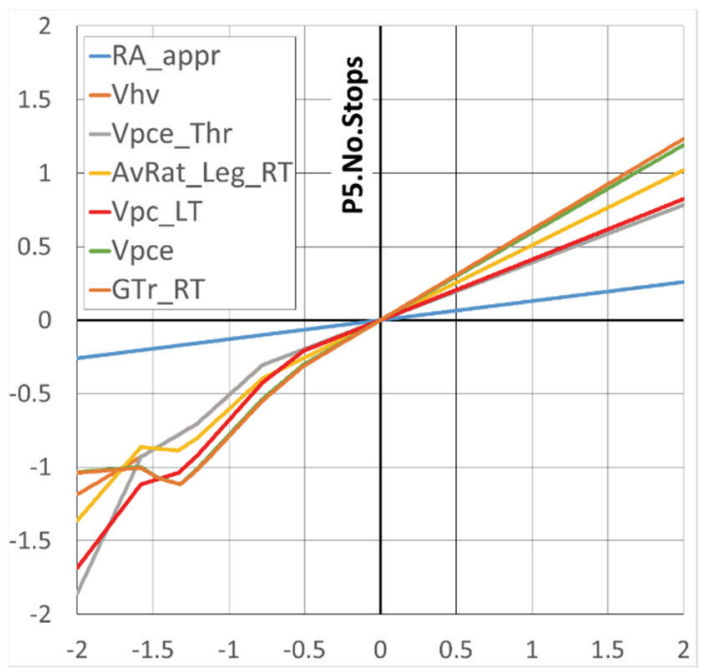

Fig. 6 - Sensitivity analysis for MARS variables in P5.No.Stops model.

Table 6. MARS model ANOVA for P5.No.Stops model.

\begin{tabular}{crrrrrc}
\hline $\begin{array}{c}\text { ANOVA } \\
\text { function }\end{array}$ & $\begin{array}{r}\text { Basis functions } \\
\text { numbers }\end{array}$ & Variables & $\begin{array}{r}\text { Standard } \\
\text { deviation }\end{array}$ & GCV & $\mathrm{R}^{2} \mathrm{GCV}$ & $\begin{array}{c}\text { Relative } \\
\text { Importance }\end{array}$ \\
\hline 1 & 4 & RA_appr & 0.05983 & 0.01243 & 0.863 & 41.74 \\
2 & 5,10 & Vhv & 0.11046 & 0.01013 & 0.888 & 25.74 \\
3 & 8 & Vpce_Thr & 0.04767 & 0.00836 & 0.908 & 12.11 \\
4 & 6,7 & AvRat_Leg_RT & 0.04250 & 0.00824 & 0.909 & 11.11 \\
5 & 3 & Vpc_LT & 0.09449 & 0.01499 & 0.835 & 57.85 \\
6 & 1,9 & Vpce & 0.12968 & 0.02280 & 0.748 & 100.00 \\
7 & 2 & GTr_RT & 0.04163 & 0.00908 & 0.900 & 17.83 \\
\hline
\end{tabular}

\subsubsection{Average Travel Time (P8)}

The average travel time per vehicle can be considered as a convenient performance tool that can be an indicator of many intersection characteristics such as dimensions, management, saturation, etc. Although the P8 MARS model is less successful than P7 according to Table 2 , it is preferred for examination because of two aspects: the average travel time can reflect the critical intersection performances average speed and delay together, and it is an indicator independent from traffic counts. Additionally, this measure has prominent discrepancy ratio statistics with a high proper percentage and balanced values for low and high percentages. The model adequately converges with $0.0078 \mathrm{GCV}$ and 10 basis functions. The efficient variables on the prediction of the average travel time are found as the average of the legbased saturation ratios (SatRat), intersection dimensions in the North-South and East-West directions (Dim_NS and Dim_EW), average green-to-cycle ratio for right turn flow 
(G/C_RT), left turn passenger car volume (Vpc_LT), difference between the numbers of enter and exit lanes (Ent-Ext_lanes), and through passing heavy vehicle volume (Vhv_Thr). The prediction equation (7) shows the critical thresholds and coefficients of these variables. The standardized forms and statistics of the basis function can also be found in Table 7. The saturation ratio for signalized intersections occurs in two different basis functions with the same threshold, 0.132. Meanwhile, a SatRat smaller than 0.132 decreases the travel time with a -0.17 coefficient, and also decreases it with a -0.33 coefficient for values over this threshold. This may arise from the signalized intersection observations with small saturations in general. The intersection dimensions are measured as the distance between stop lines for the NS and EW bounds. The related basis functions show that if the dimensions are higher than $50 \mathrm{~m}$ in the NS bound, it increases the average travel time with a 0.564 coefficient, while Dim_EW decreases it with a -0.26 for distances under $54 \mathrm{~m}$ (approximately). The green-to-cycle ratio of over 0.146 for the right turn flow decreases the average travel time with a -0.296 coefficient. The left turn passenger car volume of over 177 increases the travel time with a 1.71 coefficient, and it decreases if it is over 315 with a -1.72 coefficient. If the similar and opposite signs of the coefficients of these basis functions are considered, it can be said that the Vpc_LT effect diminishes for the counts over 315. The average left turn passenger car is 208 for the observed roundabouts; thus, this reduction is shown for some extreme observations.

P8.Ave_TrlTime $=0.041-0.33 * \max (0$, SatRat -0.132$)-1.17 * \max (0,0.132$

- SatRat $)+0.564 * \max \left(0, \operatorname{Dim}_{-} \mathrm{NS}-50.032\right)-0.296 * \max \left(0, \mathrm{G} / \mathrm{C} \_\mathrm{RT}-0.146\right)$

$+1.71 * \max (0$, Vpc_LT -176.715$)-0.78 * \max (0,0.002$ - Ent- Ext_lanes $)$

$+0.494 * \max \left(0, \mathrm{Vhv} \_\mathrm{Thr}-375.25\right)-0.26 * \max \left(0,53.974-\mathrm{Dim} \_\mathrm{EW}\right)-1.72 * \max (0$,

Vpc_LT - 314.874)

Table 7 - Basis function coefficient statistics of MARS model for P8.Ave_TrlTime.

\begin{tabular}{llrrrr}
\hline No & Basis function & Coefficient & Standard error & t statistics & P-value \\
\hline BF0 & Intercept & 0.416 & 0.026 & 15.790 & 0 \\
BF1 & $\max (0$, SatRat - 0.171) & -0.331 & 0.092 & -3.579 & 0.0007 \\
BF2 & $\max (0,0.171$ - SatRat $)$ & -1.169 & 0.167 & -6.989 & 0 \\
BF3 & $\max (0$, Dim_NS - 0.296) & 0.564 & 0.098 & 5.734 & 0 \\
BF4 & $\max (0$, G/C_RT - 0.143) & -0.296 & 0.068 & -4.376 & 0.0001 \\
BF5 & $\max (0$, Vpc_LT - 0.165) & 1.713 & 0.230 & 7.450 & 0 \\
BF6 & $\max (0,0.286$ - Ent-Ext_lanes $)$ & -0.780 & 0.194 & -4.013 & 0.0002 \\
BF7 & $\max (0$, Vhv_Thr - 0.475) & 0.494 & 0.128 & 3.865 & 0.0003 \\
BF8 & $\max (0,0.578-$ Dim_EW $)$ & -0.260 & 0.073 & -3.562 & 0.0008 \\
BF9 & $\max (0$, Vpc_LT - 0.294) & -1.716 & 0.303 & -5.662 & 0 \\
\hline
\end{tabular}


The entering lane number over exit lanes (positive Ent-Ext lanes) may be observed in improper intersection designs. The related basis function show that it decreases the average travel time if it is negative, as expected. Through passing heavy vehicle volume (Vhv_Thr) is also found to be an increase factor (with a positive 0.494 coefficient) on the travel time for the observations of over 375 .

According to the $\mathrm{t}$ statistics in Table 7, the most effective basis functions can be sorted as BF5 (Vpc_LT over knot with a positive coefficient), BF2 (SatRat under knot with a negative coefficient), and BF3 (Dim_NS over knot with a positive coefficient). According to the ANOVA analysis of the variables shown in Table 8, Vpc_LT is the most important variable for the average travel time prediction. The $\mathrm{R}^{2} \mathrm{GCV}$ value decreases to 0.649 from 0.819 when this variable is excluded. SatRat and Dim_NS follow this variable. It can be inferred that, especially the left turning passenger car volume should be maintained under 176, saturation ratio under 0.132 , and intersection dimensions under $50 \mathrm{~m}$ for an acceptable travel time performance. It is noteworthy that these threshold values may be case specific, and similar modeling processes should be performed for intersection observations from other countries or cities where the driver behavior may differ under various intersection geometry, traffic composition, and management conditions.

Table 8 - MARS model ANOVA for P8.Ave_TrlTime model.

\begin{tabular}{crrrrrr}
\hline $\begin{array}{c}\text { ANOVA } \\
\text { function }\end{array}$ & $\begin{array}{r}\text { Basis functions } \\
\text { numbers }\end{array}$ & Variables & $\begin{array}{r}\text { Standard } \\
\text { deviation }\end{array}$ & GCV & R $^{2} \mathrm{GCV}$ & $\begin{array}{r}\text { Relative } \\
\text { importance }\end{array}$ \\
\hline 1 & 8 & Dim_EW & 0.04426 & 0.00883 & 0.795 & 16.31 \\
2 & 3 & Dim_NS & 0.05497 & 0.01150 & 0.733 & 54.65 \\
3 & 6 & Ent-Ext_lanes & 0.03579 & 0.00928 & 0.785 & 23.16 \\
4 & 4 & G/C_RT & 0.04132 & 0.00968 & 0.775 & 29.14 \\
5 & 1,2 & SatRat & 0.08107 & 0.01317 & 0.695 & 76.30 \\
6 & 7 & Vhv_Thr & 0.04051 & 0.00913 & 0.788 & 20.84 \\
7 & 5,9 & Vpc_LT & 0.09253 & 0.01512 & 0.649 & 100.00 \\
\hline
\end{tabular}

A graphical sensitivity analysis of the average travel time model is shown in Fig. 7. Except for the dimensions variables (Dim_NS and Dim_EW), the lower values of all other variables appear to have a higher decreasing effect on the travel time, when it is compared with their increasing effect for higher values (according to the average) because the sensitivity slopes are generally larger at the left side. Therefore, maintaining these variables under some acceptable averages is preferable.

\subsection{Selection of Intersection Design Parameter(s)}

In this section, the model results are interpreted and new design parameters are generated to modify the existing intersections. An intersection has been selected for modification and a design is generated. 


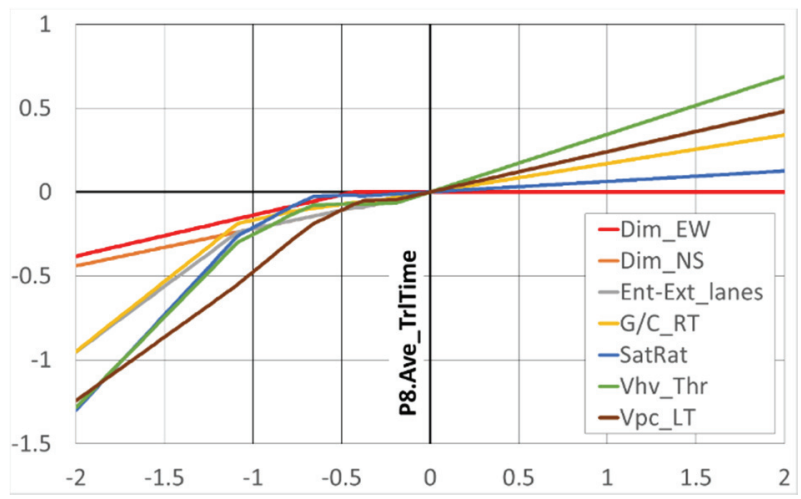

Fig. 7 - Sensitivity analysis for MARS variables in P8.Ave_TrlTime model.

Table 9 - The selected intersection design parameters and performance indicators

\begin{tabular}{|c|c|c|c|c|c|c|c|c|c|c|}
\hline \multirow{2}{*}{$\begin{array}{l}\text { Intersection } \\
\text { Performance }\end{array}$} & \multicolumn{5}{|c|}{ Intersection dimension in North-South direction (Dim_NS) } & \multicolumn{5}{|c|}{ Left turn passenger car equivalent volume (Vpc_LT) } \\
\hline & $\begin{array}{c}\text { Relative } \\
\text { Importance }\end{array}$ & No of BF & Coef. & t stat. & Basis Function(s) [BF] & $\begin{array}{c}\text { Relative } \\
\text { Importance } \\
\end{array}$ & No of BF & Coef. & t stat. & Basis Function(s) [BF] \\
\hline $\begin{array}{l}\text { P1 } \begin{array}{l}\text { Average delay } \\
\text { time per vehicle }\end{array} \\
\end{array}$ & 88.26 & 1 & 0.715 & 6.748 & $\max (0$, Dim_NS -50.032) & 21.62 & 1 & 0.368 & 3.739 & $\max \left(0, V p c \_L T-117.81\right)$ \\
\hline P2 Average speed & - & - & - & - & - & - & - & - & - & - \\
\hline P3 Total delay time & 43.64 & 1 & 0.397 & 5.073 & $\max (0$, Dim_NS -50.032) & - & - & - & - & - \\
\hline P4 $\begin{array}{l}\text { Total distance } \\
\text { traveled }\end{array}$ & - & - & - & - & - & - & - & - & - & - \\
\hline P5 Number of stops & - & - & - & - & - & 57.85 & 1 & -0.98 & -8.521 & $\max \left(0,290.241-V p c \_L T\right)$ \\
\hline $\begin{array}{l}\text { Number of } \\
\text { P6 vehicles that have } \\
\text { left the network }\end{array}$ & - & - & - & - & - & - & - & - & - & - \\
\hline P7 Total travel time & 6.22 & 1 & 0.26 & 4.174 & $\max (0$, Dim_NS -53.014) & 12 & 3 & $\begin{array}{r}-2.011 \\
1.151 \\
0.969 \\
\end{array}$ & $\begin{array}{c}-5.246 \\
3.986 \\
3.792 \\
\end{array}$ & $\begin{array}{l}\max \left(0,299.88-V p c \_L T\right) \\
\max \left(0,134.946-V p c \_L T\right) \\
\max \left(0,404.838-V p c \_L T\right)\end{array}$ \\
\hline $\begin{array}{l}\text { P8 } \begin{array}{l}\text { Average travel } \\
\text { time per vehicle }\end{array}\end{array}$ & 54.64 & 1 & 0.564 & 5.734 & $\max (0$, Dim_NS -50.032) & 100 & 2 & $\begin{array}{r}1.713 \\
-1.716\end{array}$ & $\begin{array}{r}7.445 \\
-5.662\end{array}$ & $\begin{array}{l}\max \left(0, V p c \_L T-176.715\right) \\
\max \left(0, V p c \_L T-314.874\right)\end{array}$ \\
\hline
\end{tabular}

To obtain the intersection design parameters that should be considered as a first priority, 75 explanatory variables are analyzed in terms of occurrence frequency and relative importance in the MARS predictions of eight different intersection performances. The intersection dimensions (North-South direction) and left turn passenger car volume are found to be the most frequently included parameters in the performance prediction, with inclusion in four different prediction models for both. The model statistics regarding these variables are shown in Table 9. The average delay, and the total and average travel times are typical performance indicators for these intersection features. The " $\mathrm{t}$ " statistics of the intersection dimensions are over " 4 ," and the threshold values in the basis function varies between $50-53 \mathrm{~m}$. The dimensions over these threshold values adversely affect many performance indicators with positive coefficients. The influence of the left turning passenger car volume is rather complicated especially for the travel-time-based performances. It occurs with two or more basis functions with several thresholds in the prediction models. For example, according to 
Table 9, while a Vpc_LT higher than 118 veh./h increases the average delay per vehicle with

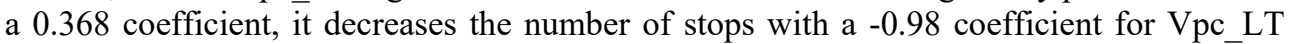
values smaller than $290 \mathrm{veh} . / \mathrm{h}$. The MARS models reflect many nonlinearities regarding the traffic count dynamics. Meanwhile, improving the traffic volume-based variables is more difficult than improving the geometric variables. This requires the implementation of network management tools such as one-way applications and left-turn constraints. Therefore, the intersection dimensions are chosen as the basic design parameter. It is worth noting that the prominence of intersection dimensions is a case-specific result, and different intersection observations and driver behaviors from another city may cause alternative conclusions. The proposed stepwise paradigm should be followed for each site study to obtain sound results.

\subsection{Testing of Intersection Design Parameter}

To test the improvement, a traffic simulation for the chosen intersection has been performed for the base case and for the proposed solution. Subsequently, before and after analysis have been conducted to evaluate the improvement.

The chosen intersection to test is called "Narin Kavsağı". It is a signalized roundabout with a diameter of $64 \mathrm{~m}$. The vehicle volumes of the intersection legs are presented in Table 10. The intersection demand in the proposed solution is assigned the same as the base case. Five arms and four routes exist for each intersection arm; therefore, 20 routes are available. The traffic speed values are calibrated by surveys as follows: passenger car, $50 \mathrm{~km} / \mathrm{h} ; \mathrm{HGV}, 30$ $\mathrm{km} / \mathrm{h}$; bus, $30 \mathrm{~km} / \mathrm{h}$; minibus, $40 \mathrm{~km} / \mathrm{h}$.

Table 10 - Vehicle input for the intersection (veh/hour)

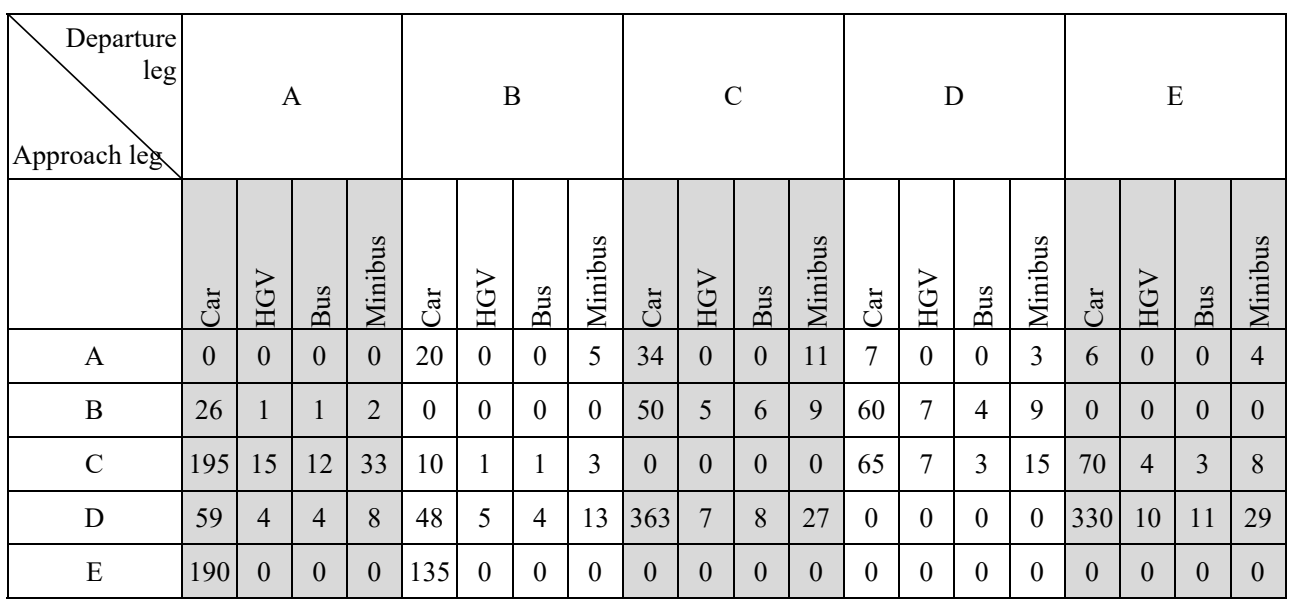

Intersection layout, signal groups and phase diagrams for base case and proposed solution are given in Fig. 8. The intersection has been simulated for the base case and subsequently redesigned in terms of dimensions. It has been transformed into an intersection that is narrower and not a roundabout, by following a new intersection design paradigm. The 
Evaluation of Intersection Properties Using MARS Method for Improving Urban ...

redesigned intersection has also been simulated in the VISSIM traffic simulation software. The visual comparison of the mentioned simulations in the $3000^{\text {th }}$ second is shown in Fig. 9 .
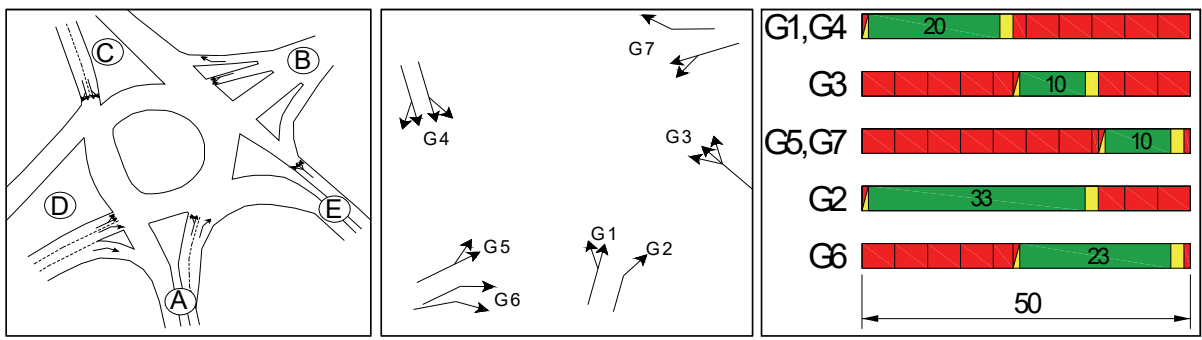

(a)

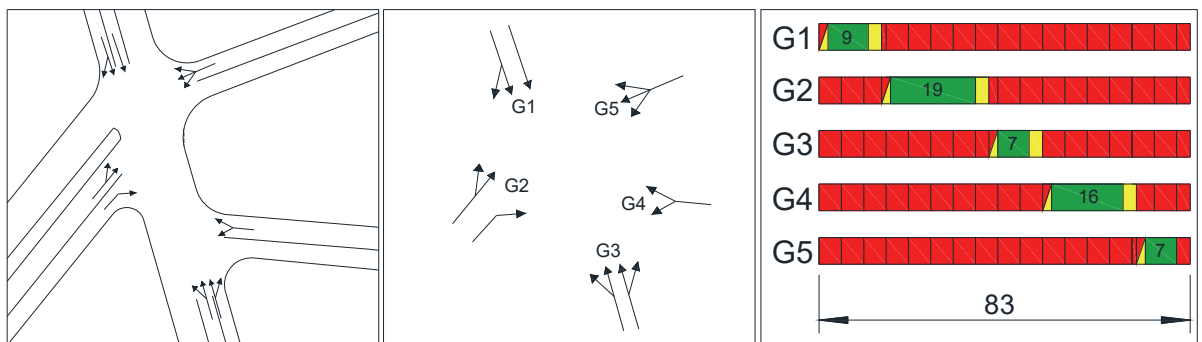

(b)

Fig. 8 - Intersection layouts, signal groups and phase diagrams of "Narin" Intersection for base case (a) and for the proposed solution (b)

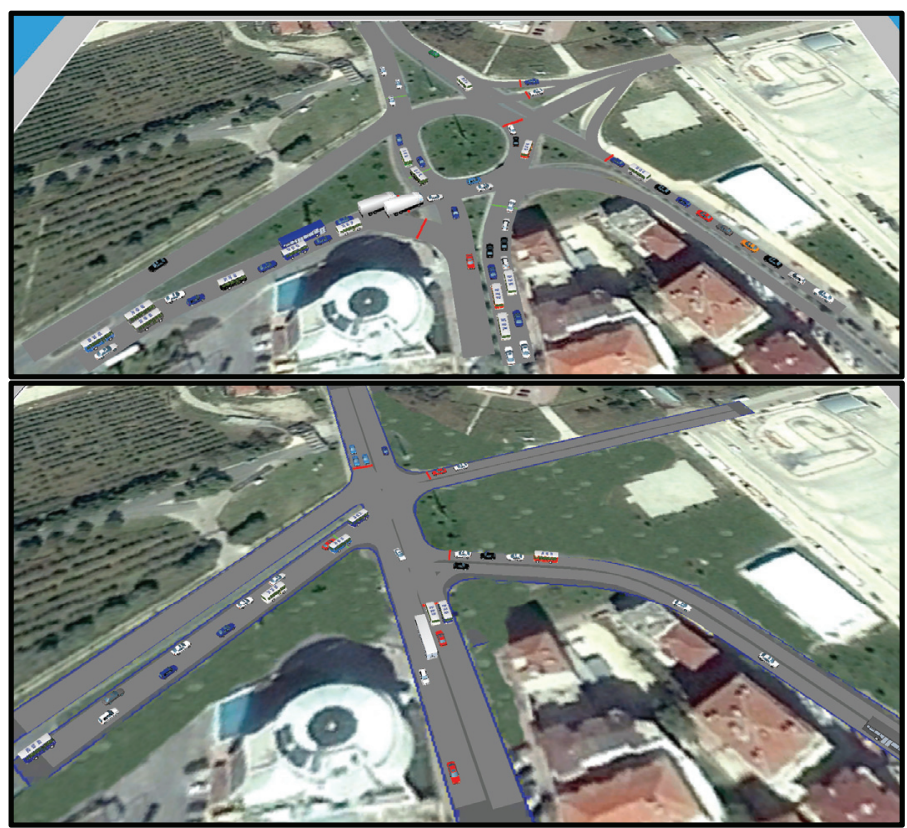

(a)

Fig. 9 - The visual comparison of intersection for base case (a) and for the proposed solution (b) $\left(3000^{\text {th }}\right.$ second of the simulation). 
As shown in Fig. 9, the dimensions of the intersection have been reduced, and the traffic jam has decreased. The performance indicators for the base case and proposed solution has been compared in Table 11. The performance indicators: average delay time per vehicle, average speed, total delay time, and total distance travelled are the primary correlated indicators with variables. Thus, the improvements on those indicators are validations of the test section. Table 11 shows noteworthy change percentages at performance indicators between $2 \%$ and $29 \%$. The increase in the total distance travelled is likely due to the rising number of vehicles that have successfully left the network. Except for that, all the performance indicators were improved. The average speed and number of stops are the most improved performances, i.e., of over $25 \%$. Consequently, using the proposed stepwise analysis, only one critical intervention can significantly improve the crucial intersection performances such as the average delay and speed.

Table 11 - Comparison of intersection performance indicators for base case and proposed solution

\begin{tabular}{llrrr}
\hline & Performance indicators & Base case & Proposed solution & Change \\
\hline P1 & Average delay time per vehicle $(\mathrm{s})$ & 45.25 & 35.93 & $-20.6 \%$ \\
P2 & Average speed $(\mathrm{km} / \mathrm{h})$ & 10.95 & 14.11 & $28.9 \%$ \\
P3 & Total delay time $(\mathrm{h})$ & 21.67 & 19.35 & $-10.7 \%$ \\
P4 & Total distance travelled $(\mathrm{km})$ & 307.00 & 386.19 & $25.8 \%$ \\
P5 & Number of stops & 2572 & 1870 & $-27.3 \%$ \\
P6 & Number of vehicles that have left the & 1698 & 1912 & $12.6 \%$ \\
P7 & Totwork & 28.04 & 27.36 & $-2.4 \%$ \\
P8 & Average travel time per vehicle (min.) & 0.99 & 0.86 & $-13.3 \%$ \\
\hline
\end{tabular}

\section{CONCLUSIONS}

In the study, a stepwise analysis briefly including intersection indexing and microsimulation, MARS-based performance prediction, selection of intersection design parameters, and testing were conducted. It was aimed to provide a holistic strategy for the description of fundamental components that decrease the intersection-based highway network performance. An average of 80 intersections in Tekirdağ were investigated with eight performance indicators. Using the MARS method, which is a promising modeling technique providing nonlinear and parametric estimations, many intersection parameters such as heavy vehicle volume, number of phase, cycle time, total entering vehicle per lane, saturation ratio, and intersection dimensions were found to be critical factors affecting the intersection performance with several threshold values. The variable of intersection dimensions of over $50 \mathrm{~m}$ was found to show the most significant effect on the average speed, average delay time per vehicle, total delay time, average delay time per vehicle, and number of stops indicators. According to the obtained result, a new intersection design was created, which was below the $50 \mathrm{~m}$ threshold. The intersection design was simulated and compared with the base case situation, and the improvement results were obtained. According to the results obtained, the 
offered intersection type was more efficient in terms of all the performance indicators, i.e., up to $29 \%$.

Many intersections, intersection characteristics, and performance indicators exist in the model. Therefore, it generated a backdrop for interpretations and subjective perspectives. It is helpful for planners to determine which design parameters to be prioritized, and which intersections should be prioritized. Many options are available for setting the mentioned priorities in the proposed model.

It is meaningful to evaluate the general characteristics of the intersections before intervening in the interchanges. The analytical nature of the assessment performed will provide a more accurate decision-making process. The mentioned model may be utilized in the urban transportation studies of local administrations. It may also be used at the lower stages of transportation planning.

There are several traffic related problems in big cities of both developing and developed countries. As known, most of these problems arise from low performance of the intersections. In such cases, specific intersection redesign proposals may provide improved results in terms of delays and congestion. The model developed in this study reveals the major intersection design parameters, which may be useful to evaluate by the planners and decision-makers in intersection redesign process. For the case area of this study, as it is stated in Table 9, planning process should start with improvements on intersection dimensions (in the north direction) and left turn volumes. The model may be utilized in new planning processes since the data generated by the model provides an essential information for decision makers.

Various policies should be developed before the interventions at crossroads in future work. These intervention policies can be determined by the proposed model or by the evaluation of many different data. Finally, since there are still many other significant variables affecting the intersection performance, the proposed model will be extended considering some other key determinants which can impact on the model.

\section{Acknowledgements}

The authors gratefully acknowledge the contribution of the PTV Traffic Mobility Logistics for the VISSIM traffic planning software. The authors are also grateful to the Metropolitan Municipality of Tekirdağ for providing the reference for the background of this paper.

\section{References}

[1] Saka, A. A., Jeihani, M., James, P. A., Estimation of Traffic Recovery Time for Different Flow Regimes on Freeways. Morgan State University Department of Transportation and Urban Infrastructure Studies School of Engineering, Report No: MD-09-SP708B4L, 2008.

[2] Ceylan, H., Bell, M. G. H., Traffic signal timing optimisation based on genetic algorithm approach, including drivers' routing. Transportation Research Part B: Methodological, 38 (4), 329-342, 2004. 
[3] Chiou, S. W., Joint optimization for area traffic control and network flow. Computers and Operations Research, 32 (11), 2821-2841, 2005.

[4] Cantarella, G. E., Vitetta, A., The multi-criteria road network design problem in an urban area. Transportation, 33 (6), 567-588, 2006.

[5] Chiou, S. W., A hybrid approach for optimal design of signalized road network. Applied Mathematical Modelling, 32 (2), 195-207, 2008.

[6] Ceylan, H., Ceylan, H., A Hybrid Harmony Search and TRANSYT hill climbing algorithm for signalized stochastic equilibrium transportation networks. Transportation Research Part C: Emerging Technologies, 25, 152-167, 2012.

[7] Szeto, W. Y., Jiang, Y., Wang, D. Z. W., Sumalee, A., A sustainable road network design problem with land use transportation interaction over time. Networks and Spatial Economics, 15 (3), 1-32, 2013.

[8] Di, Z., Yang, L., Qi, J., Gao, Z., Transportation network design for maximizing flowbased accessibility. Transportation Research Part B: Methodological, 110, 209-238, 2018.

[9] Sun, W., Wang, Y., Yu, G., Liu, H. X., Quasi-optimal feedback control for a system of oversaturated intersections. Transportation Research Part C: Emerging Technologies, 57, 224-240, 2015.

[10] Chen, P., Sun, J., Qi, H., Estimation of delay variability at signalized intersections for urban arterial performance evaluation. Journal of Intelligent Transportation Systems, 21 (2), 94-110, 2017.

[11] Liu, Y., Chang, G. L., An arterial signal optimization model for intersections experiencing queue spillback and lane blockage. Transportation Research Part C: Emerging Technologies, 19, 130-144, 2011.

[12] Lim, K., Kim, J. H., Shin, E., Kim, D. G., A signal control model integrating arterial intersections and freeway off-ramps. KSCE Journal of Civil Engineering, 15 (2), 385394, 2011.

[13] Song, X., Tao, P., Chen, L., Wang, D., Offset optimization based on queue length constraint for saturated arterial intersections. Discrete Dynamics in Nature and Society, Volume 2012, 1-13, 2012.

[14] Chen, F., Wang, L., Jiang, B., Wen, C., An Arterial Traffic Signal Control System Based on a Novel Intersections Model and Improved Hill Climbing Algorithm. Cognitive Computation, 7 (4), 464-476, 2015.

[15] Xinwu, Y., Qiaohui, W., Huibin, X., Xiaoyan, X., A coordinated signal control method for arterial road of adjacent intersections based on the improved genetic algorithm. Optik, 127 (16), 6625-6640, 2016.

[16] Stamatiadis, N., Kirk, A., Improving Intersection Design Practices Final Report - Phase I. Kentucky Transportation Center Research, Report No: KTC-10-09/SPR 380-09-1F, 2010. 
[17] Otković, I. I., Dadić, I., Comparison of delays at signal-controlled intersection and roundabout. Promet Traffic \& Transportation, 21 (3), 157-165, 2009.

[18] Persaud, B., Retting, R., Garder, P., Lord, D., Safety effects of roundabout conversions in the United States: empirical Bayes observational before-and-after study. Transportation Research Record, 1751, 1-8, 2001.

[19] Rodegerdts, L., Bansen, J., Tiesler, C., Knudsen, J., Myers, E., Roundabouts: An Informational Guide. Report 672 - Second Edition, Transportation Research Board National Cooperative Highway Research Program, Washington DC, USA, 2010.

[20] Gross, F., Lyon, C., Persaud, B., Srinivasan, R., Safety effectiveness of converting signalized intersections to roundabouts. Accident Analysis and Prevention, 50, 234$241,2013$.

[21] Kramer, R. P., New combinations of old techniques to rejuvenate jammed suburban arterials. In: Strategies to alleviate traffic congestion. Proceedings of ITE's 1987 national conference, Washington, DC, Institute of Transportation Engineers, 139-148, 1987.

[22] Hummer, J. E., Boone, J. L., The travel efficiency of unconventional arterial intersection designs. Transportation Research Record: Journal of the Transportation Research Board, 1500, 153-161, 1995.

[23] Hummer, J. E., Reid, J. D., Unconventional left-turn alternatives for urban and suburban arterials: an update. In: Transportation research circular E-C019: Urban Street Symposium Conference Proceedings, 28-30 June, Dallas, TX, 1999.

[24] Jagannathan, R., Bared, J., Design and operational performance of crossover displaced left-turn intersections. Transportation Research Record: Journal of the Transportation Research Board, 1881, 1-10, 2004.

[25] Shahi, J., Choupani, A., Modelling the operational effects of unconventional U-turns at a highway intersection. Transportmetrica, 5 (3), 173-191, 2009.

[26] El Esawey, M., Sayed, T., Unconventional USC intersection corridors: evaluation of potential implementation in Doha, Qatar. Journal of Advanced Transportation, 45 (1), 38-53, 2011.

[27] El Esawey, M., Sayed, T., Analysis of unconventional arterial intersection designs (UAIDs): state-of-the-art methodologies and future research directions. Transportmetrica A: Transport Science, 9 (10), 860-895, 2013.

[28] Autey, J., Sayed, T., El Esawey, M., Operational performance comparison of four unconventional intersection designs. Journal of Advanced Transportation, 47 (5), 536$552,2012$.

[29] Naghawi, H., Idewu, W., Analysing delay and queue length using microscopic simulation for the unconventional intersection design superstreet. Journal of the South African Institution of Civil Engineering, 56 (1), 100-107, 2014. 
[30] Xiang, Y., Li, Z., Wang, W., Chen, J., Wang, H., Li, Y., Evaluating the operational features of an unconventional dual-bay U-turn design for intersections. Plos One, 11 (7), 1-18, 2016.

[31] Lan, C-J., New optimal cycle length formulation for pretimed signals at isolated intersections. Journal of Transportation Engineering, 130 (5), 637-647, 2004.

[32] Talmor, I., Mahalel, D., Signal design for an isolated intersection during congestion. Journal of the Operational Research Society, 58 (4), 454-466, 2007.

[33] Yu, D., Tian, X., Xing, X., Gao, S., Signal timing optimization based on fuzzy compromise programming for isolated signalized intersection. Mathematical Problems in Engineering, Volume 2016, 1-12, 2016.

[34] Chang, L., Analysis of bilateral air passenger flows: A non-parametric multivariate adaptive regression spline approach. Journal of Air Transport Management, 34, $123-$ $130,2014$.

[35] Ozuysal, M., Caliskanelli, S. P., Reliability estimation of public bus routes: applicability of MARS approach. Canadian Journal of Civil Engineering, 45 (10), 852 $865,2018$.

[36] Transportation Research Board (TRB), Highway Capacity Manual. National Research Council, Washington DC, 2010.

[37] Gluck, J., Levinson, H. S., Stover, V., Impacts of access management techniques. National Cooperative Highway Research Program Report 420, Washington DC, 1999.

[38] PTV AG, VISSIM 5.40-01-User Manual. PTV Planung Transport Verkehr AG, Karlsruhe, 2011.

[39] Friedman, J.H., Multivariate adaptive regression splines. The Annals of Statistics, 19 (1), 1-67, 1991.

[40] Friedman, J. H., Estimating functions of mixed ordinal and categorical variables using adaptive splines. California: Laboratory for Computational Statistics, Technical Report No. 108, Department of Statistics, Stanford University, USA, 1991.

[41] Abdel-Aty, M., Haleem, K., Analyzing angle crashes at unsignalized intersections using machine learning techniques. Accident Analysis and Prevention, 43 (1), 461-470, 2011.

[42] Haleem, K., Gan, A., Lu, J., Using multivariate adaptive regression crash splines (MARS) to develop modification factors for urban areas freeway interchange influence. Accident Analysis and Prevention, 55, 12-21, 2013.

[43] Chang, L., Chu, H., Lin, D., Lui, P., Analysis of freeway accident frequency using multivariate adaptive regression splines. Procedia Engineering, 45, 824-829, 2012.

[44] Xu, Y., Kong, Q. J., Liu, Y., A spatio-temporal multivariate adaptive regression splines approach for short-term freeway traffic volume prediction. Proceedings of the 16th International IEEE Annual Conference on Intelligent Transportation Systems (ITSC 2013), The Hague, The Netherlands, October 6-9, 217-222 (in the proceedings book), 2013. 
[45] Xu, Y., Kong, Q. J., Klette, R., Liu, Y., Accurate and interpretable bayesian MARS for trafic flow prediction. IEEE Transactions on Intelligent Transportation Systems, 15 (6), 2457-2469, 2014.

[46] Salford Systems, SPM User Guide: Introducing MARS. https://www.salfordsystems.com/support/spm-user-guide/help/mars, 2016.

[47] TMM, Preperation of Traffic Regulation, Road and Intersection Preliminary Projects. Tekirdağ Metropolitian Municipality, Final Report (in Turkish), Tekirdağ, 2015.

[48] Jekabsons, G., ARESLab: Adaptive regression splines - toolbox for Matlab/Octave. http://www.cs.rtu.lv/jekabsons, 2016.

[49] Ozuysal, M., Caliskanelli, S. P., Tanyel, S., Baran, T., Capacity prediction for traffic circles: applicability of ANN. Proceedings of the Institution of Civil Engineers: Transport, 162 (4), 195-206, 2009. 